\title{
Functional neurological disorder: A practical guide to an elusive $\mathrm{Dx}$
}

\section{The complexity of this disorder poses a clinical challenge like few others.}

\section{PRACTICE \\ RECOMMENDATIONS}

> Avoid using stigmatizing terminology (eg, adding the prefix "pseudo" or the adjective "hysterical") to characterize a suspected functional neurological disorder (FND) or a medically unexplained disorder. (C)

$>$ Refrain from ordering functional magnetic resonance imaging as part of the routine evaluation of suspected FND. (C)

$>$ Validate the patient's concerns with an appropriate diagnostic label; use layman's terms to discuss the diagnostic parameters of FND and the cause of symptoms; and emphasize treatment possibilities and plans. (C)

Strength of recommendation (SOR)

A Good-quality patient-oriented evidence

B Inconsistent or limited-quality patient-oriented evidence

C Consensus, usual practice, opinion, disease-oriented evidence, case series

\section{CASE}

John $D_{1}$ * a 25-year-old patient with an otherwise unremarkable medical history, describes 2 months of daily headache, lowerextremity weakness, and unsteady gait that began fairly suddenly during his first deployment in the US Army. He explains that these symptoms affected his ability to perform his duties and necessitated an early return stateside for evaluation and treatment.

Mr. D denies precipitating trauma or unusual environmental exposures. He reports that, stateside now, symptoms continue to affect his ability to work and attend to personal and family responsibilities.

Asked about stressors, Mr. D notes the birth of his first child approximately 3 months ago, while he was deployed, and marital stressors. He denies suicidal or homicidal ideation.

* The patient's name has been changed to protect his identity.

\section{The challenge of identifying and managing FND}

A functional neurological disorder (FND) is a constellation of psychological, physiological, and neurological symptoms, without an identifiable organic etiology, a conscious decision, or secondary gain for the patient, ${ }^{1}$ that adversely impacts functioning in 1 or more significant life domains.

Given the high throughput of patients in primary care practices, family physicians can expect to encounter suspected cases of FND in their practices. Regrettably, however, a lack of familiarity with the disorder and its related problems (eg, nonorganic paralysis, sensory loss, nonepileptic seizures, and abnormal movements) can add as much as $\$ 20,000$ in excess direct and indirect costs of care for every such patient. ${ }^{1}$ In this article, we synthesize the recent literature on FND so that family physicians can expand their acumen in understanding, identifying, and evaluating patients whose presentation suggests FND.
Roselyn W. Clemente Fuentes, MD, FAAFP; Merima Bucaj, DO, FAAFP; Sundonia J. W. Wonnum, PhD, LCSW Eglin Family Medicine Residency, Eglin Air Force Base, FL (Dr. Clemente Fuentes); Abrazo Health Network Family Medicine Residency, Phoenix, AZ (Dr. Bucaj); Defense Health Headquarters, Falls Church, VA (Dr. Wonnum)

\section{E roselynjan.w.fuentes. mil@mail.mil}

The authors reported no potential conflict of interest relevant to this article.

The opinions and assertions contained herein are the private views of the authors and are not to be construed as official or as reflecting the views of the US Air Force Medical Department or the US Air Force at large.

doi: $10.12788 / \mathrm{jfp} .0155$ 


\section{$>$}

Remain cautious about making a diagnosis of FND by exclusion; an atypical presentation might lead to an incorrect or false-negative finding.

\section{An underrecognized entity}

A precise estimate of the prevalence of FND is difficult to determine because the disorder is underrecognized and misdiagnosed and because it is often accompanied by the confounding of psychological and physiological comorbidities. A 2012 study estimated the annual incidence of FND to be 4 to 12 cases for every 100,000 people ${ }^{2}$; in primary care and outpatient neurology settings, prevalence is $6 \%$ to $22 \%$ of all patients. ${ }^{3,4}$ Stone and colleagues identified functional neurological symptoms as the second most common reason for outpatient neurology consultation, ${ }^{5}$ with 1 nonepileptic seizure patient seen for every 6 epileptic patients, and functional weakness presenting at the same rate as multiple sclerosis. ${ }^{6}$

Demographics of patients with FND vary, depending on presenting neurological symptoms and disorder subtype. Existing data indicate a correlation between FND and younger age, female sex, physical disability, $^{7}$ and a history of abuse or trauma., ${ }^{3,8}$ A challenge in concretely ascertaining the prevalence of FND is that conditions such as fibromyalgia, chronic pelvic pain, globus hystericus, and nonepileptic seizures can also be characterized as medically unexplained functional disorders, even within the network of neurology care. ${ }^{4}$

\section{Misdiagnosis and bias are not uncommon}

Ambiguity in classifying and evaluating FND can affect physicians' perceptions, assessment, and care of patients with suggestive presenting symptoms. A major early challenge in diagnosing FND is the inconsistency of characterizing terminology (pseudoneurological, somatic, dissociative, conversion, psychogenic, hysterical, factitious, functional, medically unexplained ${ }^{9,10}$ ) and definitions in the literature. Neurological symptoms of unidentifiable organic cause can greatly diminish quality of life ${ }^{4}$; FND is a scientifically and clinically useful diagnosis for many combinations of nonrandomly co-occurring symptoms and clinical signs.

I The pitfall of misdiagnosis. Remain cautious about making a diagnosis of FND by exclusion, which might yield an incorrect or false-negative finding because of an atypical presentation. It is important to avoid misdiagnosis by prematurely closing the differential diagnosis; instead, keep in mind that a medically unexplained diagnosis might be better explained by conducting a robust social and medical history and obtaining additional or collateral data, or both, along with appropriate consultation., ${ }^{4,9}$

Misdiagnosis can lead to a circuitous and costly work-up, with the potential to increase the patient's distress. You can reduce this burden with early recognition of FND and centralized management of multidisciplinary care, which are more likely to lead to an accurate and timely diagnosis - paramount to empowering patients with access to the correct information and meaningful support needed to enhance treatment and self-care. ${ }^{9}$

I Bias, haste, and dismissal are unproductive. Even with a clear definition of FND, it is not uncommon for a physician to rapidly assess a patient's clinical signs, make a diagnosis of "unknown etiology," or openly question the veracity of complaints. Furthermore, be aware of inadvertently characterizing FND using the prefix "pseudo" or the term "hysterical," which can be psychologically discomforting for many patients, who legitimately experience inexplicable symptoms. Such pejoratives can lead to stigmatizing and misleading assessments and treatment paths ${ }^{4}$-courses of action that can cause early and, possibly, irreparable harm to the patient-physician relationship and increase the patient's inclination to go "doctor-shopping," with associated loss of continuity of care.

\section{Why is it difficult to diagnose FND?}

The latest (5th) edition of the Diagnostic and Statistical Manual of Mental Disorders (DSM-5) describes conversion, somatoform disorder, and FND synonymously. DSM-5 diagnostic criteria for conversion disorder $\operatorname{are}^{11}$ :

- a specified type of symptom or deficit of altered voluntary motor or sensory function (eg, weakness, difficulty swallowing, slurred speech, seizures)

- clinical evidence of the incompatibility of the symptom or deficit and any 
recognized neurological or medical disorder

- incapability of better explaining the symptom or deficit as another medical or mental disorder.

- The symptom or deficit causes distress or impairment that (1) is clinically significant in occupational, social, or other important areas of function or (2) warrants medical evaluation.

The overarching feature of these criteria is the inconsistency of symptoms with recognized neurological, physiological, or psychiatric conditions. Although identification of psychological factors can help clarify and provide a treatment direction, such identification is not essential for making a diagnosis of FND. Malingering does not need to be refuted as part of establishing the diagnosis. ${ }^{12}$

In contrast, the World Health Organization's ICD-10 Classification of Mental and Behavioural Disorders groups diagnostic criteria for FND among the dissociative disorders ${ }^{13}$ :

- Clinical features are specified for the individual dissociative disorder (motor, sensory, convulsions, mixed).

- Evidence is absent of a physical disorder that might explain symptoms.

- Evidence of psychological causation is present in clear temporal association with stressful events and problems or disturbed relationships, even if the patient denies such association.

Note the emphasis on psychological causation and exclusion of purposeful simulation of symptoms, as opposed to a primarily unconscious disconnection from the patient's body or environment.

ICD-10 guidelines acknowledge the difficulty of finding definitive evidence of a psychological cause and recommend provisional diagnosis of FND if psychological factors are not readily apparent. ${ }^{14}$ Of note, many patients with FND are affected psychologically by their condition, with an impact on mood, behaviors, and interpersonal interactions, although not necessarily to a clinically diagnostic degree. Therefore, a psychiatric diagnosis alone is not a necessary precursor for the diagnosis of an FND.

\section{CASE}

I History. Mr. D's history is positive for light alcohol consumption ("2 or 3 cans of beer on weekends") and chewing tobacco (he reports stopping 6 months earlier) and negative for substance abuse. The family history is positive for maternal hypertension and paternal suicide when the patient was 10 years old (no other known paternal history).

I Physical findings. The review of systems is positive for intermittent palpitations, lower-extremity weakness causing unsteady gait, and generalized headache.

Vital signs are within normal limits, including blood pressure $(120 / 82 \mathrm{~mm} \mathrm{Hg}$ ) and heart rate (110 beats $/ \mathrm{min})$. The patient is not in acute distress; he is awake, alert, and oriented $\times 3$. No murmurs are heard; lungs are clear bilaterally to auscultation. There is no tenderness on abdominal palpation, and no hepatomegaly or splenomegaly; bowel sounds are normal. No significant bruising or lacerations are noted.

I Neurology exam. Cranial nerves II-XII are intact. Pupils are equal and reactive to light. Reflexes are 2+ bilaterally. Muscle strength and tone are normal; no tremors are noted. Babinski signs are normal. A Romberg test is positive (swaying).

Mr. D has an antalgic gait with significant swaying (without falling); bent posture; and unsteadiness that requires a cane. However, he is able to get up and off the exam table without assistance, and to propel himself, by rolling a chair forward and backward, without difficulty.

\section{Conducting a diagnostic examination}

I Taking the history. Certain clues can aid in the diagnosis of FND (TABLE 1). ${ }^{15}$ For example, the patient might have been seen in multiple specialty practices for a multitude of vague symptoms indicative of potentially related conditions (eg, chronic fatigue, allergies and sensitivities, fibromyalgia, and other chronic pain). The history might include repeated surgeries to investigate those symptoms (eg, laparoscopy, or hysterectomy at an early age). Taking time and care to explore all clinical clues, patient reports, and collateral data are therefore key to making an accurate diagnosis.
Ask the patient to list all of his or her symptoms at the beginning of the interview; this can help elucidate a complex or ambiguous presentation. 
TABLE 1

Signs, symptoms, and other findings of FND ${ }^{15 a}$

\begin{tabular}{l}
\hline Alexithymia or inability to describe feelings verbally (associated with increased risk of somatization) \\
\hline Close association with psychological stressors \\
\hline Denial of possible psychiatric cause of symptoms \\
\hline History of coexisting functional disorder \\
\hline History of multiple surgeries and extensive multispecialty work-up \\
\hline History of psychiatric symptoms or disorders \\
\hline Histrionic personality traits \\
\hline Marked inconsistency on repeat physical examination \\
\hline No serious injuries associated with falls or assumed seizures \\
\hline Nonanatomic distribution of abnormalities \\
\hline Normal neurological examination \\
\hline Notable worsening of signs of the disorder in the presence of other people \\
\hline Persistent symptoms despite tailored medical treatment \\
\hline Vague or inconsistent description of symptoms by the patient \\
\hline FND, functional neurological disorder. \\
a normal neurological examination or the presence of any of the signs and symptoms listed in this TABLE does not definitively \\
exclude an organic cause. A thorough evaluation and treatment plan still need to be implemented before making a diagnosis \\
of FND.
\end{tabular}

A coexisting psychiatric diagnosis might be associated with distress from the presenting functional neurological symptoms-not linked to the FND diagnosis itself.
Note any discrepancies between the severity of reported symptoms and functional ability. A technique that can help elucidate a complex or ambiguous medical presentation is to ask the patient to list all their symptoms at the beginning of the interview. This has threefold benefit: You get a broad picture of the problem; the patient is unburdened of their concerns and experiences your validation; and a long list of symptoms can be an early clue to a diagnosis of FND.

Other helpful questions to determine the impact of symptoms on the patient's wellbeing include inquiries about ${ }^{16}$ :

- functional impairment

- onset and course of symptoms

- potential causal or correlating events

- dissociative episodes

- previous diagnoses and treatments

- the patient's perceptions of, and emotional response to, their illness

- a history of abuse.

I The physical examination to determine the presence of FND varies, depending on the functional area of impact (eg, motor, neurological, sensory, speech and swallowing). Pay particular attention to presenting signs and clues, and balance them with the patient's report (or lack of report). Endeavor to demonstrate positive functional signs, such as a positive Hoover test, which relies on the principle of synergistic muscle contraction. You might see evidence of inconsistency, such as weakness or a change in gait, under observation, that seemingly resolves when the patient is getting on and off the exam table. ${ }^{16}$ TABLE $2^{15-24}$ describes areas affected by FND, characteristics of the disorder, and related diagnostic examinations.

TABLE $3^{15,18,19}$ reviews validated special exams that can aid in making the diagnosis. Additional special tests are discussed in the literature. ${ }^{15-24}$ These tests can be helpful in narrowing the differential diagnosis but have not been validated and should be used with caution.

Some clinical signs associated with FND might be affected by other factors, including socioeconomic status, limited access to health care, low health literacy, poor communication skills, and physician bias. Keep these factors in mind during the visit, to avoid contributing further to health disparities among groups of patients affected by these problems. 
TABLE 2

The physical examination in suspected FND ${ }^{15-24}$

\begin{tabular}{|c|c|c|c|c|}
\hline $\begin{array}{l}\text { Functional area } \\
\text { of impact }\end{array}$ & Diagnosis & $\begin{array}{l}\text { Alternative } \\
\text { terminology }\end{array}$ & Characteristics & $\begin{array}{l}\text { Diagnostic observations and } \\
\text { examinations }\end{array}$ \\
\hline \multirow[t]{3}{*}{ Motor } & $\begin{array}{l}\text { Functional gait } \\
\text { abnormality }\end{array}$ & $\begin{array}{l}\text { Hysterical gait } \\
\text { Astasia-abasia }\end{array}$ & $\begin{array}{l}\text { Ambulatory dysfunction } \\
\text { Variable gait pattern, with } \\
\text { rapid fluctuation over } \\
\text { minutes } \\
\text { Other patterns that do not } \\
\text { commonly duplicate those of } \\
\text { neurological disability } \\
\text { Involves uneconomic } \\
\text { postures, slowness, fatigue, } \\
\text { and trembling } \\
\text { Able to catch self before } \\
\text { falling }{ }^{16}\end{array}$ & $\begin{array}{l}\text { Normal reflexes, muscle tone, and } \\
\text { strength } \\
\text { Absence of fall-related injury } \\
\text { Motor inconsistency }{ }^{18,19 b} \\
\text { Dragging monoplegic gait }{ }^{16,19 b} \\
\text { Uneconomic posture (eg, camptocormia } \\
\text { [bent-spine syndrome]) }{ }^{16} \\
\text { "Walking-on-ice" pattern }{ }^{16} \\
\text { Pseudoataxia }{ }^{16} \\
\text { Sudden knee-buckling } \\
\text { Normal neurological function on } \\
\text { magnetic resonance imaging } \\
\text { Chair test }{ }^{18,19 b}\end{array}$ \\
\hline & $\begin{array}{l}\text { Functional } \\
\text { paralysis or } \\
\text { weakness }\end{array}$ & Pseudo-paralysis & $\begin{array}{l}\text { Sudden onset of symptoms } \\
\text { with involvement of a single } \\
\text { limb or half of the body } \\
\text { Weakness does not follow } \\
\text { anatomic patterns }{ }^{16} \\
\text { Inconsistency on repeat } \\
\text { examination }\end{array}$ & $\begin{array}{l}\text { Hoover test }{ }^{18,19 b} \\
\text { Abductor sign }{ }^{18,19 b} \\
\text { Abductor finger sign }{ }^{18,19 b} \\
\text { Spinal injury test }{ }^{18,19 b} \\
\text { Motor inconsistency } \\
\text { Normal reflexes, muscle tone, and } \\
\text { sphincter function } \\
\text { Collapsing weakness (intermittent } \\
\text { weakness) }^{16,19} \\
\text { Co-contraction of antagonist muscle } \\
\text { Negative Babinski signs }{ }^{16} \\
\text { Functional magnetic resonance imaging } \\
\text { (left hemisphere or anterior and medial }_{\text {prefrontal activation) }}^{17}\end{array}$ \\
\hline & $\begin{array}{l}\text { Functional } \\
\text { movement } \\
\text { disorder }\end{array}$ & $\begin{array}{l}\text { Psychogenic } \\
\text { movement } \\
\text { disorder }\end{array}$ & $\begin{array}{l}\text { Can mimic tremor, } \\
\text { parkinsonism, myoclonus, } \\
\text { dystonia, tics, and dyskinesia, } \\
\text { but has atypical onset, } \\
\text { course, or manifestations }{ }^{16} \\
\text { Rapid onset (unusual in } \\
\text { organic disease) }^{16}\end{array}$ & $\begin{array}{l}\text { Motor inconsistency }{ }^{18,19 b} \\
\text { Abnormal movement stops when } \\
\text { distracted } \\
\text { Variability of unwanted movements in } \\
\text { distribution, frequency, and amplitude }{ }^{16} \\
\text { Increased weighted amplitude (organic } \\
\text { tremor decreases) } \\
\text { Dystonia waxes and wanes }{ }^{16} \\
\text { Electromyography }{ }^{20}\end{array}$ \\
\hline
\end{tabular}

\section{CASE}

The work-up over the next month for Mr. D includes numerous studies, all yielding results that are negative or within normal limits: visual acuity; electrocardiography and an event monitor; laboratory testing (including a complete blood count, comprehensive metabolic panel, thyroid-stimulating hormone, creatine kinase, erythrocyte sedimentation rate, Creactive protein, vitamin $B_{12}$, folate, and vita- 
TABLE 2

\section{The physical examination in suspected $\mathrm{FND}^{15-24}$ ( cont' $^{\prime} d$ )}

\begin{tabular}{|c|c|c|c|c|}
\hline $\begin{array}{l}\text { Functional area } \\
\text { of impact }\end{array}$ & Diagnosis & $\begin{array}{l}\text { Alternative } \\
\text { terminology }\end{array}$ & Characteristics & $\begin{array}{l}\text { Diagnostic observations and } \\
\text { examinations }\end{array}$ \\
\hline \multirow[t]{2}{*}{ Neurological } & $\begin{array}{l}\text { Nonorganic } \\
\text { coma }\end{array}$ & Pseudo-coma & $\begin{array}{l}\text { Alteration of consciousness } \\
\text { precipitated by stress and } \\
\text { presence of an observer } \\
\text { Slumps to floor without } \\
\text { hitting head"1 } \\
\text { Offers resistance on physical } \\
\text { exam } \\
\text { Uncooperative upon "wake } \\
\text { up" }\end{array}$ & $\begin{array}{l}\text { Normal pupils, corneal reflexes, plantar } \\
\text { reflexes, and sphincters } \\
\text { Bell phenomenon, in which the eyes roll } \\
\text { up when the lids are raised-unlike in } \\
\text { true coma, in which the eyes remain in a } \\
\text { neutral position }{ }^{21} \\
\text { Avoids unpleasant stimuli } \\
\text { Caloric testing with cold water, } \\
\text { nystagmus with nonorganic coma, due } \\
\text { to intact cerebral cortex and brainstem } \\
\text { (might have nausea and vomiting }{ }^{22} \text { ) }\end{array}$ \\
\hline & $\begin{array}{l}\text { Nonepileptic } \\
\text { seizures }\end{array}$ & $\begin{array}{l}\text { Hysterical } \\
\text { seizures } \\
\text { Psychogenic } \\
\text { seizures }\end{array}$ & $\begin{array}{l}\text { Paroxysmal and involuntary } \\
\text { events with changes in } \\
\text { the level of consciousness, } \\
\text { behavior, motor activity, and } \\
\text { autonomic function }{ }^{23} \\
\text { Seizures are frequent and } \\
\text { occur in front of an observer }{ }^{24} \\
\text { Characteristic pelvic thrusting, } \\
\text { side-to-side head shaking, } \\
\text { asymmetric limb-shaking }{ }^{24} \\
\text { Can act out or recall what } \\
\text { occurred during the seizure } \\
\text { Long duration, eyes closed, } \\
\text { asynchronous movements, } \\
\text { frequent recurrence in the } \\
\text { same context }{ }^{24} \\
\text { Occurrence of seizures waxes } \\
\text { and wanes } \\
\text { No post-ictal confusion }\end{array}$ & $\begin{array}{l}\text { Normal electroencephalographic activity } \\
\text { (including when sleep deprived and } \\
\text { during } 24 \text {-hour monitoring) } \\
\text { Tip-of-tongue biting (instead of lateral } \\
\text { biting) } \\
\text { Clenched teeth, as opposed to open } \\
\text { mouth, during "tonic" phase } \\
\text { Consider measuring the serum prolactin } \\
\text { level within } 20 \text { min of a seizure (the } \\
\text { level is increased } 300 \% \text { in epilepsy); } \\
\text { however, false-positive results are seen } \\
\text { with syncope and false-negatives are } \\
\text { seen with partial seizures; also, the test is } \\
\text { often performed incorrectly }{ }^{16}\end{array}$ \\
\hline \multirow[t]{2}{*}{ Sensory } & $\begin{array}{l}\text { Functional } \\
\text { ophthalmologic } \\
\text { syndromes }\end{array}$ & $\begin{array}{l}\text { Pseudo-blindness } \\
\text { Pseudo- } \\
\text { ophthalmologic } \\
\text { syndrome }\end{array}$ & - & $\begin{array}{l}\text { Normal pupillary response and } \\
\text { optokinetic nystagmus (fixation reflex) } \\
\text { Unable to sign name or bring fingers } \\
\text { together in front of eyes, which the } \\
\text { patient should be able to do }{ }^{16}\end{array}$ \\
\hline & $\begin{array}{l}\text { Functional } \\
\text { anesthesia }\end{array}$ & $\begin{array}{l}\text { Numbness or } \\
\text { anesthesia }\end{array}$ & $\begin{array}{l}\text { All sensory modalities } \\
\text { (touch, pain, vibration, } \\
\text { proprioception) disappear at } \\
\text { a discrete border (joint, skin } \\
\text { crease, midline)—unlike true } \\
\text { sensory loss, in which borders } \\
\text { overlap }^{16}\end{array}$ & $\begin{array}{l}\text { Increased pulse ( } 20-30 \text { beats/min) or } \\
\text { withdrawal from painful stimuli applied } \\
\text { to the "numb" part"15 } \\
\text { Hemisensory syndrome or midline } \\
\text { splitting } \\
\text { Vibrator } \\
\text { sternum, or pelvis with the tuning fork } \\
\text { test is physiologically impossible due to } \\
\text { bone conduction" } \\
\text { Nonanatomic sensory loss } \\
\text { Migrating sensory loss }{ }^{19 b} \\
\text { Erroneous identification with a } \\
\text { proprioception test of the big toe }\end{array}$ \\
\hline
\end{tabular}


TABLE 2

The physical examination in suspected $\mathrm{FND}^{15-24}\left(\right.$ cont' $\left.^{\prime} d\right)$

\begin{tabular}{|c|c|c|c|c|}
\hline $\begin{array}{l}\text { Functional area } \\
\text { of impact }\end{array}$ & Diagnosis & $\begin{array}{l}\text { Alternative } \\
\text { terminology }\end{array}$ & Characteristics & $\begin{array}{l}\text { Diagnostic observations and } \\
\text { examinations }\end{array}$ \\
\hline $\begin{array}{l}\text { Speech and } \\
\text { swallowing }\end{array}$ & $\begin{array}{l}\text { Functional } \\
\text { aphonia } \\
\text { Functional } \\
\text { dysarthria } \\
\text { Functional } \\
\text { dysphagia }\end{array}$ & $\begin{array}{l}\text { Globus hystericus } \\
\text { Hysterical } \\
\text { aphonia }\end{array}$ & - & $\begin{array}{l}\text { Muteness } \\
\text { Normal cough } \\
\text { Normal laryngoscopy }{ }^{15} \\
\text { Pressured whispering }{ }^{16} \\
\text { Sensation of something in throat }{ }^{16} \\
\text { Stutter or extremely slow speech with } \\
\text { long pauses }^{16}\end{array}$ \\
\hline
\end{tabular}

FND, functional neurological disorder.

a The authors caution against using "pseudo"/" hysterical" in conversation with patients, although these terms may still be encountered in the literature.

b See TABLE 3.

min D); magnetic resonance imaging of the brain and lumbar spine; lumbar puncture; and electromyography.

The score on the 9-item Patient Health Questionnaire for depression is 4 (severity: "none or minimal"); on the 7-item Generalized Anxiety Disorder scale, 0 ("no anxiety disorder").

Referral. A neurology work-up of headache, lower extremity weakness, and unsteady gait to address several diagnostic possibilities, including migraine and multiple sclerosis, is within normal limits. A cardiology work-up of palpitations is negative for arrhythmias and other concerning findings.

Mr. D declines psychiatric and psychological evaluations.

\section{Building a differential diagnosis is a formidable task}

The differential diagnosis of FND is vast. It includes neurological, physiological, and psychiatric symptoms and disorders; somatization; and malingering (TABLE 4). ${ }^{6}$ Any disorder or condition in these areas that is in the differential diagnosis can be precipitated or exacerbated by stress; most, however, do not involve loss of physical function. ${ }^{12}$ In addition, the diagnosis of an FND does not necessarily exclude an organic disorder.

A patient's presentation becomes complicated-and more difficult to treat-when functional symptoms and an unrelated underlying or early-stage neurological condi- tion coexist. For example, a patient with epilepsy might also have dissociative seizures atop their organic disorder. Neurological disease is considered a risk factor for an overlying FND-just as the risk of depression or anxiety runs concurrently with other chronic diseases. $^{14}$

- Focus on clinical signs to narrow the differential. A thorough social and medical history and physical examination, as discussed earlier, help narrow the differential diagnosis of organic and medically unexplained disorders. Well-defined imaging or laboratory protocols do not exist to guide physicians to a definitive diagnosis, however.

- Psychiatric conditions can coexist with the diagnosis of FND, but might be unrelated. A systematic review of the literature showed that $17 \%$ to $42 \%$ of patients with FND had a concurrent anxiety disorder. Depression disorders were co-diagnosed in $19 \%$ to $71 \%$ of patients with FND; dissociative and personality disorders were noted, as well. ${ }^{25}$ However, coexisting psychiatric diagnosis might more likely be associated with distress from the presenting functional neurological symptoms, not linked to the FND diagnosis itself. ${ }^{12}$ This shift in understanding is reflected in the description of FND in the DSM-5. ${ }^{11}$

\section{CASE}

Mr. D reports debilitating headaches at return office visits. Trials of abortive triptans provide no relief; neither do control medications 


\section{TABLE 3}

\section{Specialized tests for FND ${ }^{15,18,19}$}

\begin{tabular}{|c|c|c|}
\hline $\begin{array}{l}\text { Functional area } \\
\text { of impact }\end{array}$ & $\begin{array}{l}\text { Validated test } \\
\text { (sensitivity, } \\
\text { specificity) }\end{array}$ & Instructions \\
\hline \multirow[t]{7}{*}{ Motor } & $\begin{array}{l}\text { Hoover test } \\
\left(94 \%, 99 \%^{15,18,19}\right)\end{array}$ & $\begin{array}{l}\text { Relies on the principle of synergistic muscle contraction. } 18,19 \\
\text { 1. Place a hand under the heel of the patient's impaired leg, while pressing down } \\
\text { on the good leg with the other hand. Ask the patient to lift the good leg against } \\
\text { resistance. If you feel counter-pressure under the impaired leg, this normally means } \\
\text { that the leg is not paralyzed from an organic cause. } \\
\text { 2. Switch hand positions. Ask the patient to lift the impaired leg. If you do not feel } \\
\text { counter-pressure under the heel of the good leg, the patient is not being compliant. }{ }^{15,19}\end{array}$ \\
\hline & $\begin{array}{l}\text { Abductor sign } \\
\left(100 \%, 100 \%^{15,18,19}\right)\end{array}$ & $\begin{array}{l}\text { Instruct the patient to abduct each leg. Oppose this movement with your hands placed } \\
\text { on the lateral surfaces of the patient's legs. When the paretic leg is abducted, the good } \\
\text { leg stays in organic paresis but moves in the hyperadducting direction in nonorganic } \\
\text { paresis. } 15,18,19\end{array}$ \\
\hline & $\begin{array}{l}\text { Abductor finger sign } \\
\left(100 \%, 100 \%{ }^{18,19}\right)\end{array}$ & $\begin{array}{l}\text { Relies on the same principle as the Hoover sign. } \\
\text { Test the abduction of fingers in the healthy hand. The fifth finger of the presumed } \\
\text { affected hand will display synkinetic abduction. }{ }^{18,19}\end{array}$ \\
\hline & $\begin{array}{l}\text { Spinal injury test } \\
\left(100 \%, 97.9 \%{ }^{18,19}\right)\end{array}$ & $\begin{array}{l}\text { Passively position the legs in a flexed posture when the patient is lying in bed. When } \\
\text { the paretic leg falls, the test is considered negative; when it stays in a flexed posture, } \\
\text { the test is considered positive. }{ }^{18,19}\end{array}$ \\
\hline & $\begin{array}{l}\text { Collapsing give-way } \\
\text { weakness } \\
\left(63 \%, 97 \%{ }^{18,19}\right)\end{array}$ & $\begin{array}{l}\text { The limb collapses from a normal position with a light touch, or normal strength is } \\
\text { developed and suddenly "gives way" (collapses). } ._{18,19}\end{array}$ \\
\hline & $\begin{array}{l}\text { Co-contraction of } \\
\text { antagonist muscles } \\
\left(17 \%, 100 \%^{18,19}\right)\end{array}$ & $\begin{array}{l}\text { During strength testing, an antagonist muscle contracts simultaneously when an } \\
\text { agonist muscle contracts voluntarily. } \\
\text { The sign is positive if simultaneous contraction of agonist and antagonist muscles } \\
\text { results in little or no movement. } \\
\text { The sign can be measured with surface electromyography. }{ }^{18,19}\end{array}$ \\
\hline & $\begin{array}{l}\text { Motor inconsistency } \\
\left(13 \%, 98 \%{ }^{18,19}\right)\end{array}$ & $\begin{array}{l}\text { The patient's assertion of the impossibility of a given movement of a muscle even } \\
\text { though a different movement using the same muscle is possible. } \\
\text { Example: A patient with complete plegia of a limb when tested supine stands on the } \\
\text { previously plegic limb and walks out of examination room. }{ }^{18,19}\end{array}$ \\
\hline
\end{tabular}

(beta-blockers, coenzyme Q10, magnesium, onabotulinumtoxinA [Botox], topiramate, and valproate). Lower-extremity weakness and unsteadiness are managed with supportive devices, including a cane, and physical therapy.

\section{Importance of establishing} a multidisciplinary approach

The complexity of FND lends itself to a multidisciplinary approach during evaluation and, eventually, for treatment. The assessment and diagnostic intervention that you provide, along with the contributions of consulted specialists (including neurology, physical and occupational therapy, psychiatry, psychology, and other mental health professionals) establishes a team-based approach that can increase the patient's sense of support and reduce excessive testing and unnecessary medications, surgeries, and other treatments. ${ }^{26}$

Family physicians are in the ideal position to recognize the patient's functional capacity and the quality of symptoms and to provide timely referral (eg, to Neurology and Psychiatry) for confirmation of the diagnosis and then treatment.

Evidence-based treatment options include: - psychotherapy, with an emphasis on 
TABLE 3

\begin{tabular}{|c|c|c|}
\hline $\begin{array}{l}\text { Functional area } \\
\text { of impact }\end{array}$ & $\begin{array}{l}\text { Validated test } \\
\text { (sensitivity, } \\
\text { specificity) }\end{array}$ & Instructions \\
\hline \multirow[t]{4}{*}{ Sensory } & $\begin{array}{l}\text { Midline splitting } \\
\left(20 \%, 93 \%{ }^{19}\right)\end{array}$ & $\begin{array}{l}\text { Sensory loss of half the body (with face, trunk, arm, and leg involvement) with a clear } \\
\text { edge on the midline. The sign is positive if the patient reports precise splitting of } \\
\text { sensation in the midline during sensory exam. }{ }^{19}\end{array}$ \\
\hline & $\begin{array}{l}\text { Splitting } \\
\text { of vibration } \\
\left(95 \%, 14 \%{ }^{19}\right)\end{array}$ & $\begin{array}{l}\text { Placing a tuning fork on the right or left side of the forehead or the sternum is thus } \\
\text { expected to be felt identically because the same bone is involved. The sign is positive } \\
\text { if there is a reported difference in the sensation of the tuning fork placed over the left } \\
\text { side, compared to the right side, of the sternum or frontal bone. }{ }^{19}\end{array}$ \\
\hline & $\begin{array}{l}\text { Nonanatomic } \\
\text { sensory loss } \\
\left(74 \%, 100 \%{ }^{19}\right)\end{array}$ & $\begin{array}{l}\text { Diminished sensation fitting a nondermatomal pattern. } \\
\text { Classically, the following findings are considered nonanatomic }{ }^{19} \text { : } \\
\text { - truncal deficits that have only an anterior level but not a posterior level } \\
\text { - sharply demarcated boundaries at the shoulder or at the groin } \\
\text { - sensory loss follows the strict outline of a stocking-glove distribution unilaterally } \\
\text { - involvement of only half of a limb. }\end{array}$ \\
\hline & $\begin{array}{l}\text { Inconsistency or } \\
\text { changing pattern } \\
\text { of sensory loss } \\
\left(79 \%, 70 \%{ }^{19}\right)\end{array}$ & $\begin{array}{l}\text { Inconsistency and nonreproducibility of sensory signs in repeated sensory testing. } \\
\text { No precise description exists of how to perform the repeated tests. }{ }^{19}\end{array}$ \\
\hline \multirow[t]{2}{*}{ Gait } & $\begin{array}{l}\text { Dragging } \\
\text { monoplegic gait } \\
\left(8.4 \%, 100 \%{ }^{19}\right)\end{array}$ & The leg is dragged at the hip behind the body instead of performing circumduction. ${ }^{19}$ \\
\hline & $\begin{array}{l}\text { Chair test } \\
\left(89 \%, 100 \%{ }^{19}\right)\end{array}$ & $\begin{array}{l}\text { The inability to stand or walk despite normal function in bed, in a patient who was } \\
\text { observed performing well in propelling a chair. } \\
\text { The sign is positive when the patient is observed propelling a swivel chair better than } \\
\text { walking. }{ }^{19}\end{array}$ \\
\hline
\end{tabular}

FND, functional neurological disorder.

cognitive behavioral therapy

- physical therapy

- psychopharmacology

- promising combinations of physical and psychological treatment to improve long-term functionality. ${ }^{27}$

\section{A promising}

\section{diagnostic tool}

The most significant update in the FND literature is on functional neuroimaging for assessing the disorder. Early findings suggest an intricate relationship between mind and body regarding the pathological distortion in FND. And, there is clear evidence that neuroimaging-specifically, functional magnetic resonance imagingshows changes in brain activity that correspond to the patient's symptom report. That said, imaging is not the recommended standard of care in the initial work-up of FND because of its cost and the fact that the diagnosis is principally a clinical undertaking. ${ }^{17,28}$

\section{Call to action}

I Offer a generous ear. Begin the diagnostic pursuit by listening carefully and fully to the patient's complaints, without arriving at a diagnosis with unwarranted bias or haste. This endeavor might require support from other clinical staff (eg, nurses, social workers, case managers) because the diagnostic process can be arduous and lengthy.

Convey the diagnosis with sensitivity. Inquire about the patient's perceptions and impairments to best personalize your diagnostic explanations. Delivery of the diagnosis 


\section{TABLE 4}

\section{Differential diagnosis of $\mathrm{FND}^{6}$}

\begin{tabular}{l}
\hline Neurological and physiological conditions \\
\hline Autoimmune limbic encephalitis \\
\hline Cortical blindness (secondary to stroke) \\
\hline Epilepsy \\
\hline Laryngeal dystonia \\
\hline Multiple sclerosis \\
\hline Movement disorders \\
\hline Spinal or brain injuries or disorders \\
\hline Stiff person syndrome \\
\hline Stroke \\
\hline Psychiatric conditions \\
\hline Anxiety disorders \\
\hline Body dysmorphic disorder \\
\hline Depersonalization and de-realization disorder \\
\hline Depressive disorders \\
\hline Hypochondriasis \\
\hline Panic attacks \\
\hline Psychosis \\
\hline Other \\
\hline Factitious disorder \\
\hline latrogenic \\
\hline Malingering \\
\hline Substance use \\
\hline
\end{tabular}

There is clear evidence that functional magnetic resonance imaging reveals changes in brain activity that correspond with the report of symptoms.
I Key tenets of managing care for patients who have been given a diagnosis of FND include:

- nonjudgmental, positive regard

- meaningful expression of empathy

- multidisciplinary coordination

- avoidance of unnecessary testing and harmful treatments

- descriptive and contextual explanations of the diagnosis.

Last, keep in mind that the course of treatment for FND is potentially prolonged and multilayered.

\section{CASE}

After many visits with his family physician and the neurology and cardiology specialists, as well as an extensive work-up, the physician approaches Mr. D with the possibility of a diagnosis of FND and proposes a multidisciplinary plan that includes:

- a course of physical and occupational therapy

- development of individualized cognitive behavioral tools

- weekly personal and marital counseling

- initiation of a selective serotonin reuptake inhibitor for anxiety

- monthly visits with his family physician.

Months after his return from deployment for evaluation and treatment, Mr. D is able to return to military duty. He reports that his quality of life has improved.

JFP

compliance with further testing and treatment of what is generally a persistent and treatment-resistant disorder; poor delivery of diagnostic information can impair the patient-physician relationship and increase the risk of disjointed care. Many patients find that improved patient-physician communication is therapeutic. ${ }^{29}$

I Let the patient know that you're taking her seriously. Validate patient concerns with a nonstigmatizing diagnostic label; discuss the diagnostic parameters and cause of symptoms in layman's terms; and emphasize the potential for reversibility. ${ }^{30}$ Some patients are not satisfied with having a diagnosis of FND until they are reassured with normal results of testing and provided with referral; even then, some seek further reassurance.
CORRESPONDENCE

Roselyn W. Clemente Fuentes, MD, FAAFP, Eglin Family Medicine Residency, 307 Boatner Road, Eglin AFB, FL 32547; roselynjan.w.fuentes.mil@mail.mil.

\section{References}

1. Konnopka A, Schaefert R, Heinrich S, et al. Economics of medically unexplained symptoms: a systematic review of the litera-

2. Carson AJ, Brown R, David AS, et al; on behalf of UK-FNS Functional (conversion) neurological symptoms: research since the millennium. J Neurol Neurosurg Psychiatry. 2012;83: 842-850.

3. Stone J, Carson A, Duncan R, et al. Who is referred to neurology clinics?-the diagnoses made in 3781 new patients. Clin Neurol Neurosurg. 2010;112:747-751.

4. Evens A, Vendetta L, Krebs K, et al. Medically unexplained neurologic symptoms: a primer for physicians who make the initial encounter. Am J Med. 2015;128:1059-1064.

5. Stone J, Reuber M, Carson A. Functional symptoms in neurology: mimics and chameleons. Pract Neurol. 2013;13:104-113.

6. Stone J, Warlow C, Sharpe M. The symptom of functional ture. Psychother Psychosom. 2012;81:265-275. 
weakness: a controlled study of 107 patients. Brain. 2010;133. 1537-1551.

7. Carson A, Stone J, Hibberd C, et al. Disability, distress and unemployment in neurology outpatients with symptoms 'unexplained by organic disease'. J Neurol Neurosurg Psychiatry. 2011;82: 810-813.

8. Fink P, Hansen MS, Oxhøj M-L. The prevalence of somatoform disorders among internal medical inpatients. J Psychosom Res. 2004;56:413-418.

9. Thomas LE. Are your patient's medically unexplained symptoms really "all in her head"? Med Hypotheses. 2012;78:542-547.

10. Ding JM, Kanaan RAA. What should we say to patients with unexplained neurological symptoms? How explanation affects offence. J Psychosom Res. 2016;91:55-60.

11. Diagnostic and Statistical Manual of Mental Disorders (DSM-5). 5th ed. American Psychiatric Association; 2013.

12. Stone J, LaFrance WC Jr, Levenson JL, et al. Issues for DSM-5: Conversion disorder. Am J Psychiatry. 2010;167:626-627.

13. The ICD-10 Classification of Mental and Behavioural Disorders: Clinical Descriptions and Diagnostic Guidelines. World Health Organization; 1994. Accessed January 21, 2021. www.who.int/ classifications/icd/en/bluebook.pdf

14. Stone J, Carson A, Duncan R, et al. Which neurological diseases are most likely to be associated with "symptoms unexplained by organic disease." J Neurol. 2012;259:33-38.

15. Shaibani A, Sabbagh M. Pseudoneurologic syndromes: recognition and diagnosis. Am Fam Physician. 1998;57:2485-2494.

16. Stone J, Carson A, Sharpe M. Functional symptoms and signs in neurology: assessment and diagnosis. J Neurol Neurosurg Psychiatry. 2005;76(suppl 1):i2-i12.

17. Vuilleumier P. Brain circuits implicated in psychogenic paralysis in conversion disorders and hypnosis. Neurophysiol Clin. 2014;44:323-337.

18. McKee $\mathrm{K}$, Glass S, Adams C, et al. The inpatient assessment and management of motor functional neurological disorders: an interdisciplinary perspective. Psychosomatics. 2018;59:358-368.

19. Daum C, Hubschmid M, Aybek S. The value of 'positive' clini- cal signs for weakness, sensory and gait disorders in conversion disorder: a systematic and narrative review. J Neurol Neurosurg Psychiatry. 2014;85:180-190.

20. Brown P, Thompson PD. Electrophysiological aids to the diag nosis of psychogenic jerks, spasms, and tremor. Mov Disord. 2001;16:595-599.

21. Ludwig L, McWhirter L, Williams S, et al. Functional coma. In Hallett M, Stone J, Carson A, eds. Handbook of Clinical Neurology: Volume 139: Functional Neurologic Disorders. 1st ed. Academic Press; 2016:313.

22. Miller NR, Subramanian PS, Patel VR. Walsh and Hoyt's Clinical Neuro-ophthalmology. 3rd ed. Wolters Kluwer; 2016:512-513.

23. Takazaki K, Stransky AD, Miller G. Psychogenic nonepileptic seizures: diagnosis, management, and bioethics. Pediatr Neurol. 2016;62:3-8.

24. Sahaya K, Dholakia SA, Sahota PK. Psychogenic non-epileptic seizures: a challenging entity. J Clin Neurosci. 2011;18:1602-1607.

25. Gelauff J, Stone J, Edwards M, et al. The prognosis of functional (psychogenic) motor symptoms: a systematic review. J Neurol Neurosurg Psychiatry. 2014;85:220-226.

26. Kranick SM, Gorrindo T, Hallett M. Psychogenic movement disorders and motor conversion: a roadmap for collaboration between neurology and psychiatry. Psychosomatics. 2011;52:109-116.

27. Edwards MJ, Bhatia KP. Functional (psychogenic) movement disorders: merging mind and brain. Lancet Neurol. 2012;11: 250-260.

28. Burgmer M, Kugel H, Pfleiderer B, et al. The mirror neuron system under hypnosis-brain substrates of voluntary and involuntary motor activation in hypnotic paralysis. Cortex. 2013;49: 437-445.

29. van Bokhoven MA, Koch $H$, van der Weijden T, et al. Influence of watchful waiting on satisfaction and anxiety among patients seeking care for unexplained complaints, Ann Fam Med. 2009;7:112-120

30. Stone J, Carson A, Hallet M. Explanation as treatment for functional neurologic disorders. Handb Clin Neurol. 2016;139: 543-553. absence of appropriate physician oversight. ${ }^{8}$ This issue is so concerning to me that I coauthored a book on the subject. ${ }^{8}$ I encourage all physicians to educate themselves on this topic and make practice decisions with the evidence in mind.

\section{References}

1. Laurant M, van der Biezen M, Wijers N, et al. Nurses as substitutes for doctors in primary care. Cochrane Database of Syst Rev. 2018;(7):CD001271. doi: 10.1002/14651858.CD001271.pub3

2. Flynn, BC. The effectiveness of nurse clinicians' service delivery. AJPH. 1974;64:604-611.

3. Hughes DR, Jiang M, Duszak R. A comparison of diagnostic im aging ordering patterns between advanced practice clinicians and primary care physicians following office-based evaluation and management visits. JAMA Intern Med. 2015;175:101-107. doi:10.1001/jamainternmed.2014.6349

4. Muench, U, Perloff J, Thomas C, et al. Prescribing practices by nurse practitioners and primary care physicians: a descriptive analysis of Medicare beneficiaries. Journal of Nursing Regulation. 2017;8:21-30. doi: https://doi.org/10.1016/S2155-8256(17) 30071-6

5. Sanchez GV, Hersh AL, Shapiro DJ, et al. Outpatient antibiotic prescribing among United States nurse practitioners and physician assistants. Open Forum Infect Dis. 2016;10:ofw168. doi: 10.1093/ofid/ofw168.

6. Lohr RH, West CP, Beliveau M, et al. Comparison of the quality of patient referrals from physicians, physician assistants, and nurse practitioners. Mayo Clin Proc. 2013;88:1266-1271. doi:10.1016/j. mayocp.2013.08.013

7. Nault A, Zhang C, Kim KM, et al. Biopsy use in skin cancer diagnosis: comparing dermatology physicians and advanced practice professionals. JAMA Dermatol. 2015;151:899-901. doi:10.1001/ jamadermatol.2015.0173

8. Al-Agba N, Bernard R. Patients at Risk: The Rise of the Nurse Practitioner and Physician Assistant in Healthcare. Universal Publishers; 2020 .

\section{WE WANT TO HEAR FROM YOU!}

Have a comment on an article, editorial, or department? You can send it by

1. E-MAIL: jfp.eic@gmail.com

2. FAX: 973-206-9251 or

3. MAIL: The Journal of Family Practice, 7 Century Drive, Suite 302, Parsippany, NJ 07054

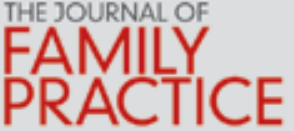

LETTERS SHOULD BE 200 WORDS OR LESS. THEY WILL BE EDITED PRIOR TO PUBLICATION. 